\title{
MEDIÇÃO DE ALDEÍDOS USANDO IMPINGER E CARTUCHO EM UM MOTOCICLO FLEXFUEL E EM VEICULO LEVE DO CICLO DIESEL.
}

\author{
Harlen Feijó Bório ${ }^{1}$, Renato Penteado ${ }^{1}$, Luiz Carlos Daemme ${ }^{1}$, Marina Scheiffer \\ Nadolny ${ }^{1}$, Ricardo Godoi ${ }^{2}$, Lucas Steffenhagen ${ }^{3}$ \\ ${ }^{1}$ Institutos Lactec \\ ${ }^{2}$ Universidade Federal do Paraná - UFPR \\ ${ }^{3}$ Universidade Tecnológica Federal do Paraná - UTFPR \\ E-mails: hfborio@lactec.org.br, renato@lactec.org.br, luiz.carlos@lactec.org.br, \\ marina.nadolny@lactec.org.br, ricardo.godoi@ufpr.br, lucaslucas1993@hotmail.com
}

\section{RESUMO}

A legislação brasileira estabelece limites máximos de emissão de aldeídos em veículos leves e prescreve sua determinação por cromatografia líquida de alta eficiência, com o uso de frascos lavadores de gases.

A determinação de valores típicos de aldeídos em motores Diesel da Fase P7 foi determinada pelo CONAMA por meio da Resolução 403/2008 e a AEA criou um Grupo de Trabalho que recomendou o procedimento de coleta de aldeídos presentes nos gases de exaustão, tanto por frascos lavadores de gases como por cartuchos.

Para o caso de motocicletas, ainda não existe uma legislação que defina os limites de emissão para os aldeídos, bem como o procedimento de coleta e quantificação.

O uso de cartuchos para a coleta de gases pode trazer vantagens em relação aos frascos lavadores de gases e por essa razão motivou esta pesquisa, cujo objetivo foi desenvolver um dispositivo para realizar a coleta de aldeídos presentes nos gases de escapamento por cartuchos e que possa ser utilizado tanto nos testes de emissões em salas de ensaios de motores e de chassis.

O resultado do trabalho foi o desenvolvimento e montagem de uma unidade móvel autônoma para coleta de gases de escape usando cartuchos.

O presente artigo apresenta os resultados do desempenho da unidade móvel autônoma, comparando-os com o procedimento normatizado para determinação de aldeídos nos gases de escape com uso de frascos lavadores de gases.

Para avaliar a influência de diferentes motorizações e combustíveis, foram testados um veículo leve do ciclo Diesel e um motociclo Flex abastecido com gasolina A22 e etanol hidratado de referência (EHR), usando como meio de coletas as metodologias europeias de ensaio em banco de chassis. 
A conclusão principal é que existe uma correlação aceitável entre as duas técnicas de coleta e medição de aldeídos presentes nos gases de escape veiculares.

\section{INTRODUÇÃO}

A necessidade de se preservar o meio ambiente como condição crucial de manutenção da vida vem sendo discutida nas últimas décadas com maior ênfase, abordando os mais variados temas, tais como: emissões de poluentes, aquecimento global, gerenciamento de resíduos, etc. Com o aumento considerável da frota de veículos automotores, principalmente nos grandes centros urbanos, tem como consequência um maior consumo de combustíveis e aumento das emissões de poluentes, com isso, este assunto ganha relevância.

Neste contexto o setor automotivo brasileiro, particularmente no que diz respeito aos motores do ciclo Diesel, passa por um momento de grandes desafios e oportunidades. Em novembro de 2008 o Governo Federal, por meio do IBAMA, publicou a Resolução CONAMA № 403/2008 [1] que dispõe sobre a nova fase de exigência do Programa de Controle da Poluição do Ar por Veículos AutomotoresPROCONVE para veículos pesados novos (Fase P-7).

Os dispositivos da referida Resolução e a entrada em vigor dos requisitos legais pertinentes à Fase P7 impacta de forma expressiva os setores industriais, de projeto de motores, na produção de combustíveis e de sistemas de tratamento dos gases gerados no processo de combustão.

A Resolução 403/2008 determina que se passe a medir os teores de aldeídos gerados em motor Diesel. Estes compostos são nocivos à saúde humana e ao meio ambiente. Os aldeídos são produtos químicos, resultantes da decomposição parcial dos alcoóis, altamente reativos, gerados a partir do processo de combustão nos motores. A combustão incompleta gera diversos poluentes, entre eles os aldeídos [2, 3]. Esses compostos causam danos e irritação às vias respiratórias e olhos dos seres humanos, bem como são classificados como cancerígenos (formaldeído) e potencialmente cancerígenos (acetaldeído) [4, 5, 6]. Devida à instabilidade química, esses compostos podem participar de várias reações na atmosfera, formando outros compostos. Dentre eles se destaca o ozônio, que além de ser oxidante é um precursor do efeito estufa [3, 7].

Atualmente a legislação brasileira define metodologia de coleta e medição, pela NBR 12026 [8] e os limites máximos de emissão de aldeídos são regulamentados desde 1992, somente para veículos leves do ciclo Otto [9]. A coleta dos compostos carbonílicos é realizada durante a execução do teste em dinamômetro de chassis, onde as emissões são diluídas em um amostrador de volume constante, de acordo com a NBR 6601 [10], procedimento baseado no CFR "Code of Federal Regulations", em um ciclo padronizado, denominado de FTP 75 [11, 12].

A metodologia prevê o uso de frascos lavadores de gases, doravante neste artigo denominados de impingers por tratar-se de jargão técnico usado em laboratórios de 
emissões veiculares. Os impingers são preenchidos com solução absorvente de DNPH (2,4-dinitrofenilhidrazina) em acetonitrila para amostragem dos compostos carbonílicos. O método se aplica para medir massas entre 0,02 e $200 \mu \mathrm{g}$. Para separação dos compostos utiliza-se a técnica de cromatografia em fase líquida, com detecção por ultravioleta. A acetonitrila é produzida em baixo volume em escala mundial, o que tende a elevar seu preço. O descarte deste reagente também deve atender a legislação por ser classificado como um produto tóxico e inflamável. Estas restrições suscitaram estudos de aplicação de outras técnicas de coleta de gases que pudessem ser adotadas alternadamente à normatizada no Brasil [13].

Outra forma de coleta de gases muito conhecida na Química Analítica tem como base o uso de cartuchos. Por exemplo, o CFR preconiza a coleta de aldeídos por cartuchos impregnados com DNPH [14].

Alguns autores mediram compostos não regulamentados, como formaldeído, BTX e metanol não queimado, usando a espectrometria de massas, com um analisador multi componente, extraindo o gás de exaustão diretamente do tubo de descarga e direcionando ao analisador [15][16].

Melo et at.[17] apresentaram uma proposta para medição de aldeídos em motores do ciclo Diesel, efetuando a amostragem dos gases de exaustão por meio de cartuchos impregnado com DNPH. Daemme et al.[[18]8] coletaram aldeídos dos gases de escape de motocicletas pelo método de impingers, baseando-se na NBR 12026, concluíndo que a metodologia de amostragem e quantificação desses compostos é factível para essa categoria de veículo automotor. Penteado et al.[19] mediram aldeídos pela técnica de FTIR em motociclos.

Alguns laboratórios vinculados ao setor automotivo assim como centros de pesquisa têm realizado estudos para a determinação de aldeídos em Diesel [20] [21] [22] [23]. Tais estudos versam sobre a forma de coleta destes compostos nos gases de escape, que possui um alto grau de dificuldade, tendo em vista o perfil dinâmico e transiente do fluxo destes gases ao saírem dos coletores de escapamento dos motores. Neste ponto, o fluxo não é laminar, os gases estão em temperatura da ordem de 250 graus e sua coleta exige cuidados com o transporte e com a natural condensação em função do contato com o ar na temperatura ambiente.

O objetivo deste trabalho foi desenvolver uma unidade móvel autônoma de coleta de amostras de gases de exaustão por meio de cartuchos para a medição de aldeídos, e para aplicação em um laboratório de emissões veiculares.

\section{METODOLOGIA}

A metodologia adotada para a realização deste trabalho está dividida em duas etapas. A primeira etapa trata da construção de uma unidade móvel autônoma para coleta de gases de exaustão por meio de cartuchos e, na segunda, este dispositivo é submetido a uma bateria de testes laboratoriais para verificação de sua eficácia. 
A seguir cada uma das etapas que compõe a Metodologia será descrita.

2.1 Construção da unidade móvel autônoma para coleta de gases de exaustão por meio de cartuchos

Para realizar a coleta de gases de exaustão em cartuchos foi construída uma unidade móvel autônoma para aquisitar alíquotas dos gases de escape com as seguintes propriedades:

a) Controle da vazão de gás de zero a $5 \mathrm{~L} / \mathrm{min}$;

b) Medição da vazão;

c) Controle da oscilação do fluxo de ar. A oscilação é provocada pela bomba e deve ser controlada para permitir uma medição adequada do fluxo.

d) Estabilização térmica do sistema. Este aspecto é importante para a medição correta da vazão.

e) Controle do fluxo do gás no cartucho em concordância com o ciclo de emissões adotado. Ou seja, respeitando os tempos e intervalos de aquisição de gases prescritos pelos variados ciclos de emissão existentes.

f) Ter mobilidade de instalação para utilização em laboratórios de teste de veículos e motores.

A Figura 1 apresenta a montagem em bancada de instrumentação. Nesta fase o conjunto estava em desenvolvimento e sendo submetido a testes de verificação da funcionalidade de cada componente.

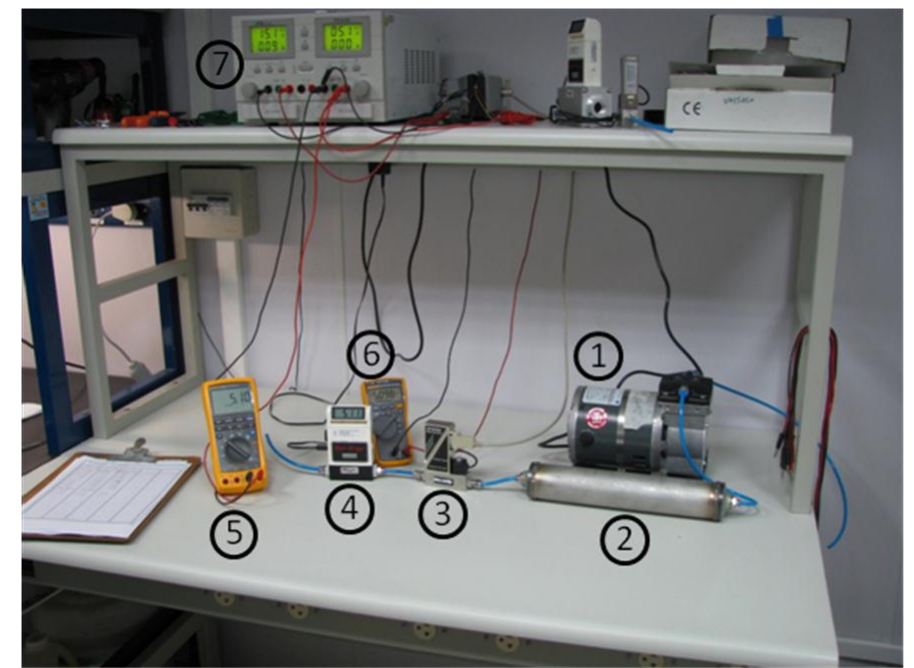

Figura 1 Montagem, em bancada de instrumentação, dos componentes do conjunto.

Fonte: Os autores (2014)

A Tabela 1 relaciona os componentes do conjunto.

Tabela 1 Bancada de instrumentação com componentes para coleta de gases de exaustão

\begin{tabular}{|l|l|}
\hline 1 - Bomba de vácuo & 2 - Reservatório \\
\hline $3-$ Medidor de vazão (mass flow) & $4-$ Medidor de vazão \\
\hline $5-$ Multímetro a & 6 - Multímetro b \\
\hline 7 - Fonte de alimentação & \\
\hline
\end{tabular}

Fonte: Os autores (2014) 


\subsubsection{Descrição e função dos componentes:}

Descrição e função dos componentes:

Bomba de vácuo

\section{Descrição}

Fabricante: Dia-Vac pumps

Modelo: R221-BT-AA1

Potência: $1 / 8$ HP

Função

Promover a circulação dos gases pelo componente de coleta (cartucho), pelo medidor e controlador de vazão (Mass Flow).

Reservatório

\section{Descrição}

Construído com um tubo de aço galvanizado contendo conexões nas extremidades. Função

Regularizar o fluxo dos gases para permitir a medição adequada da vazão. $O$ componente foi instalado para reduzir a pulsação de fluxo de gás, na passagem pelo medidor de vazão, provocada pela bomba de vácuo.

Medidor de Vazão (Mass Flow)

Descrição

Fabricante: Parker

Modelo: 201-FKASVYAA

Precisão: $\pm 1 \%$ em toda a escala

Linearidade: $\pm 1,5 \%$ em toda a escala

Função

Controlar e medir a vazão de gás que passa pelo componente de coleta (cartucho)

Medidor de vazão

Descrição

Fabricante: SIERRA Instrumentos

Modelo: 822-1-OV1-PV2-V4

Precisão: $\pm 1,5 \%$ em toda a escala

Linearidade: $\pm 0,5 \%$ em toda a escala

Função

Trata-se de um segundo medidor de vazão, instalado em série no sistema, para conferir os resultados de medição de vazão do mass flow.

Multímetro a

Descrição

Fabricante: Fluke

Modelo: Fluke 114

Resolução: 0,001 V

Precisão: $\pm 0,5 \%$

Função

Leitura do valor de tensão de referência para controle de vazão. 


\section{Multímetro b}

Descrição

Fabricante: Fluke

Modelo: Fluke 789

Resolução: 0,001 V

Precisão: $\pm 0,1 \%$

Função

Leitura do valor de tensão proporcional à vazão.

Fonte de alimentação

Descrição

Fabricante: ICEL

Modelo: OS-600

Saída: 0-30 Vcc e 0-6 A

Função

Alimentação elétrica do sistema.

\subsubsection{Testes em bancada de instrumentação}

Os testes foram realizados para verificação e aprendizado do sistema. Em um primeiro momento foi projetado um sistema simples contendo uma bomba para circulação da amostra e um medidor de vazão para a coleta. Porém, já nos primeiros testes utilizando os cartuchos, verificou-se que este sistema não possuía estabilidade nem confiabilidade de medição. Por esta razão optou-se por colocar uma bomba de vácuo e um controlador/medidor de vazão.

Em seguida foram efetuados novos testes cujos resultados apresentaram uma significativa melhora de estabilidade. Foram, ainda, implementados mais alguns componentes como o reservatório e válvulas. O reservatório eliminou a pulsação do fluxo de gás provocado pela bomba de vácuo. As válvulas foram necessárias, pois se notou que o sistema de medição de vazão necessita de um tempo mínimo de fluxo constante para estabilizar para, então, se iniciar a coleta da amostra. O gás passa por uma linha paralela (by-pass) àquela onde se encontra instalado 0 cartucho, permitindo que o sistema de medição de vazão estabilize.

\subsubsection{Unidade móvel autônoma de coleta de aldeídos}

As Figuras 2 e 3 apresentam imagens da unidade de coleta de gases de exaustão. A Figura 2 mostra um detalhe da unidade móvel autônoma. A Figura 3 mostra a unidade móvel autônoma conectada ao amostrador de volume constante (CVS).

A bomba de vácuo retira uma amostra do gás de escapamento já diluída pelo sistema CVS, no caso de um banco de teste de veículos ou do Smart Sampler no caso de um banco de motores. Como o sistema de coleta (cartucho) e o medidor de vazão estão dispostos em série com a bomba, a amostra de gás também percorre ambos. O cartucho retém os aldeídos na forma de derivado carbonílico, e o mass flow mede e controla a vazão. O volume amostrado é calculado pelo produto entre o valor de vazão e o tempo de amostragem, efetuando-se a correção para temperatura padrão de $20^{\circ} \mathrm{C}$. 


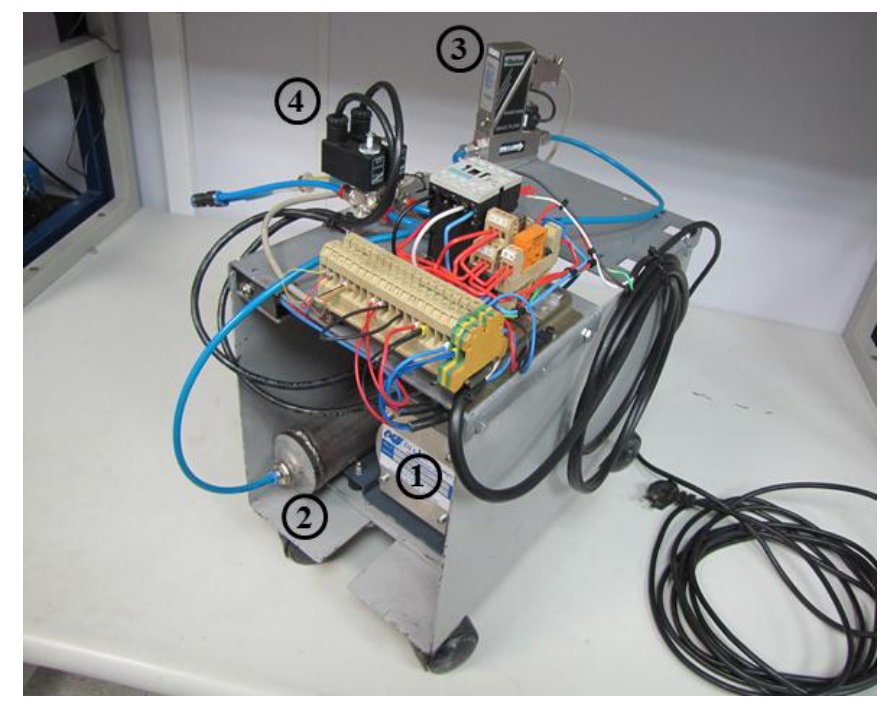

Figura 2 Fotografia da unidade móvel autônoma de coleta de aldeídos, onde (1) é a bomba de vácuo; (2) é o reservatório de gás; (3) o medidor de vazão e (4) o conjunto de válvulas.

Fonte: Os autores (2014)

A Figura 3 apresenta a unidade móvel autônoma conectada ao CVS.

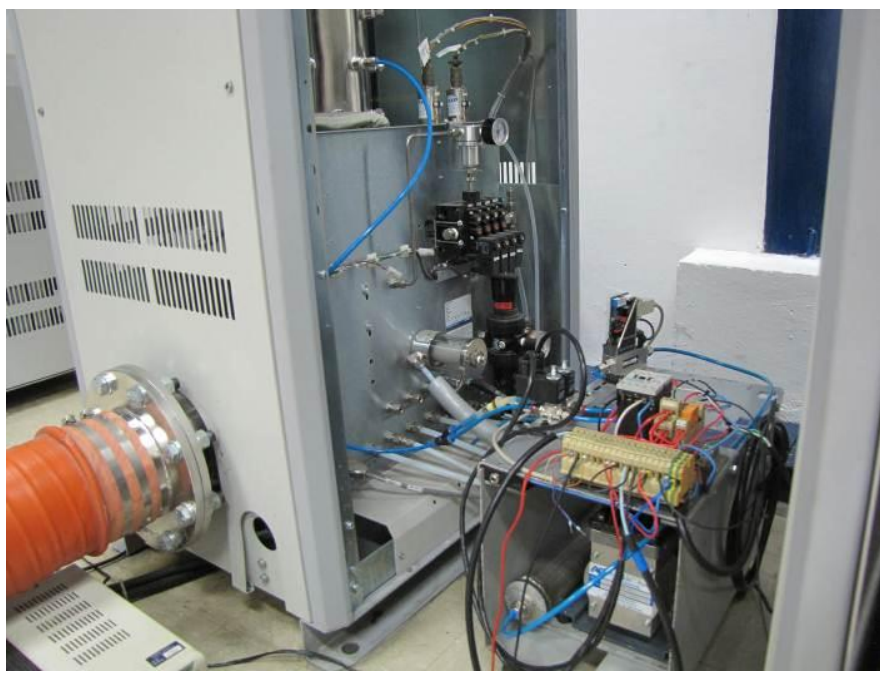

Figura 3 Fotografia da unidade móvel autônoma de coleta de aldeídos integrada ao CVS. Fonte: Os autores (2014)

2.2 Testes de veículos em laboratório de emissões usando impingers e cartuchos

\subsubsection{Métodos de teste}

Os testes foram realizados no LEME, Laboratório de Emissões Veiculares dos Institutos Lactec, localizado em Curitiba, Brasil.

Os testes consistiram na coleta simultânea dos gases por impingers e por cartuchos. Os cartuchos possuem as seguintes características técnicas:

Marca: Waters

Modelo: Sep-Pak DNPH-Silica Cartrige Plus-Short Body (360 mg)

Série: WAT037500 
A coleta por cartucho foi executada seguindo dois métodos, abaixo descritos.

No método 1, o cartucho foi inserido na linha disponível do painel de amostragem de aldeídos, marca Horiba, destinada originalmente para medição de álcool não queimado. Este teste foi realizado para avaliar o desempenho comparativo entre $o$ cartucho e os impingers no que diz respeito à coleta de aldeídos. Como ambos os ramais do painel Horiba possuem o mesmo tipo de instrumentação, as condições operacionais foram mantidas tanto para o cartucho como para os impingers. Este arranjo pode ser observado na Figura 4.

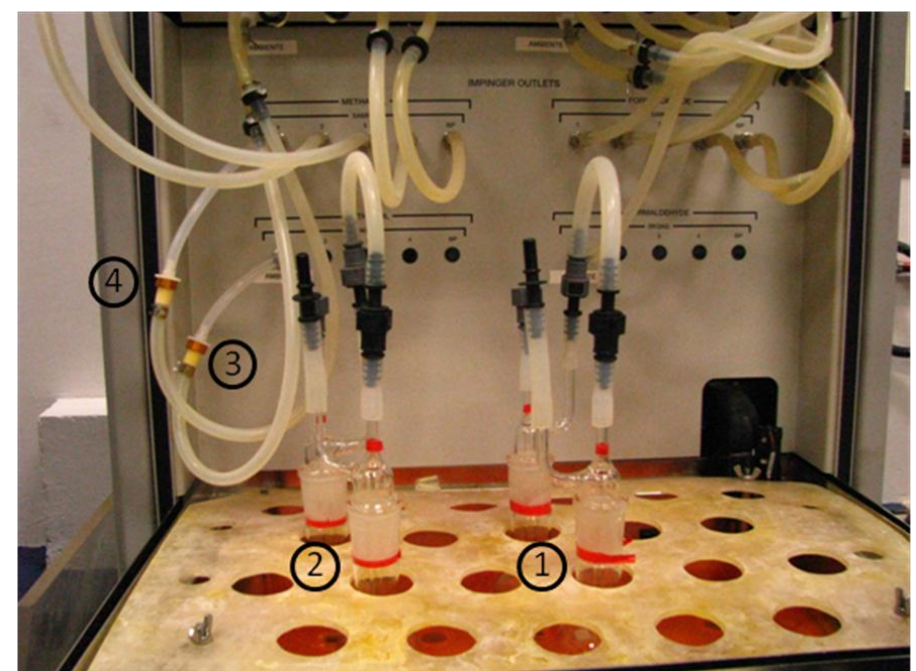

Figura 4 Método 1 de coleta de gases de exaustão por meio de impingers (1 e 2) e cartuchos (3 e 4). Fonte: Os autores (2014)

No método 2, a coleta por cartucho foi realizada pela unidade móvel (2). Simultaneamente foi executada a coleta por impingers (1). Este teste teve o objetivo de avaliar o desempenho da unidade móvel autônoma relação aos impingers e o arranjo é apresentado na Figura 5.

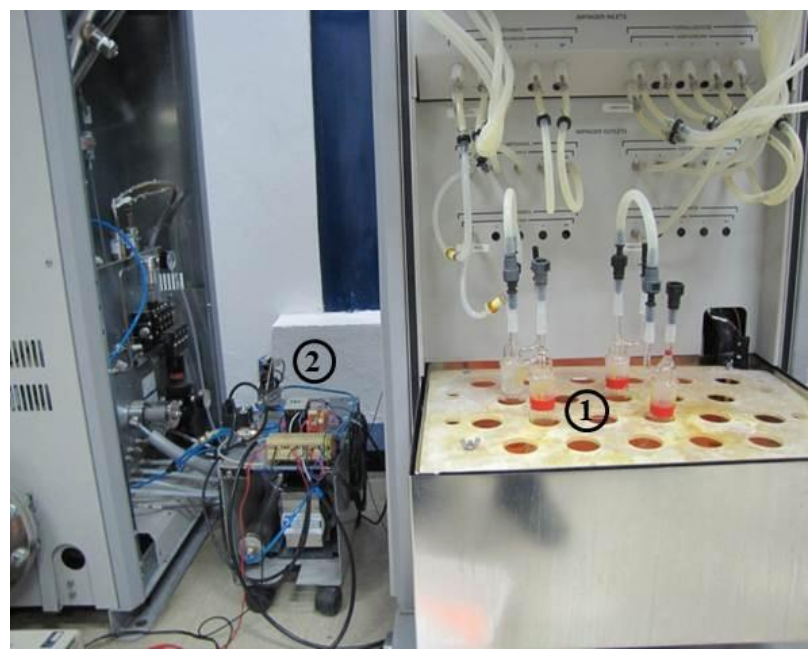

Figura 5 Método 2 de coleta de gases de exaustão por meio de impingers (1) e cartucho. A coleta por cartucho foi executada na unidade móvel autônoma (2).

Fonte: Os autores (2014) 
$\mathrm{Na}$ instalação da unidade móvel autônoma, uma alíquota de amostra do gás é retirada do mesmo ponto de coleta utilizado pelo sistema convencional para os impingers (1). A amostra de gás passa pelo sistema de coleta (by-pass ou cartucho) (3) e retorna ao Amostrado de Volume Constante - CVS (2), como mostra a Figura 6.

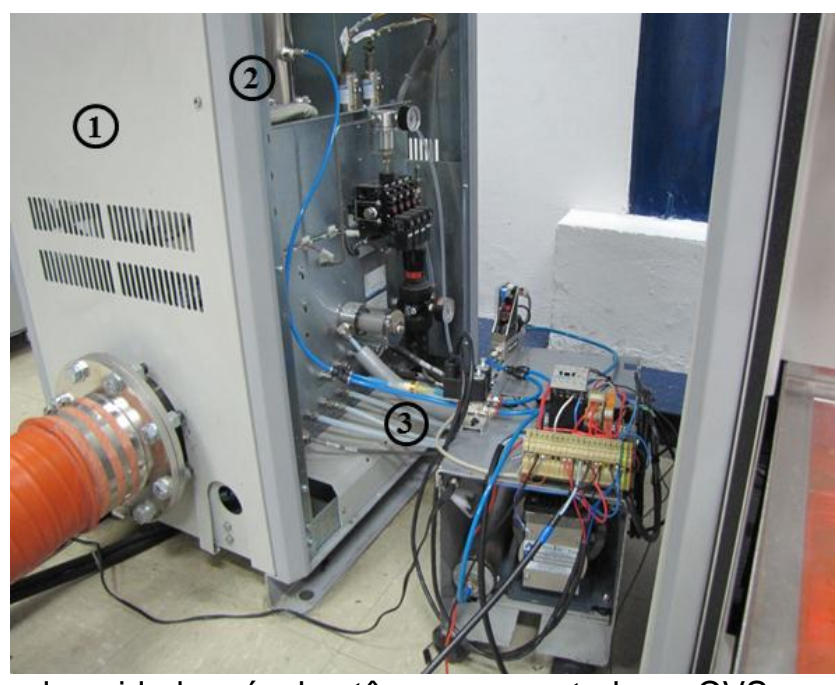

Figura 6 Instalação física da unidade móvel autônoma conectada ao CVS.

Fonte: Os autores (2014)

Para integrar a unidade móvel autônoma ao banco de chassis foi desenvolvido um programa em Labview, com uma interface gráfica que permite a inversão entre as linhas de coleta de gases e a aquisição do valor de vazão. Foi utilizado um computador portátil e uma placa de interface NI USB-6009 (1), conforme Figura 7, para tanto foram implementadas entradas e saídas, com a seguinte especificação:

Entrada analógica: Recebe sinal de 0 a $5 \mathrm{~V}$ proporcional a vazão de gás amostrado, esse sinal é enviado pelo mass flow.

Saída digital: Permite inverter linha de amostragem, 0 = by-pass, $1=$ linha cartucho.

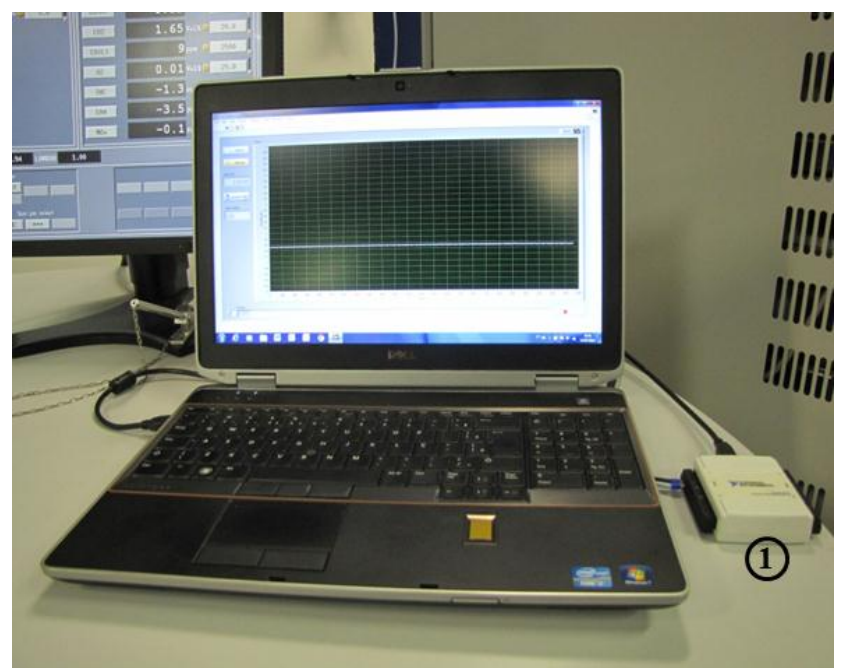

Figura 7 Conjunto para integração da unidade móvel autônoma ao banco de chassis. A interface digital está ilustrada em (1)

Fonte: Os autores (2014) 


\subsubsection{Características dos veículos testados}

Foram executados testes em um veículo leve de passageiros com motor do ciclo Diesel e um motociclo flexfuel.

As características principais dos veículos utilizados são:

Veiculo leve de passageiro, ciclo diesel, motor 1.5 turbo alimentado, com catalisador do tipo DOC.

Motociclo 150 cc, Flexfuel, ano 2011, injeção eletrônica, catalisador TWC.

\subsubsection{Características dos combustíveis}

\begin{tabular}{|l|c|c|}
\hline \multirow{2}{*}{ Característica } & \multicolumn{2}{c|}{ Combustível } \\
\cline { 2 - 3 } & EHR & A22 \\
\hline Massa especifica a 20ํ $\mathrm{C}\left(\mathrm{kg} / \mathrm{m}^{3}\right)$ & 808,1 & 742,7 \\
\hline Teor de etanol (\% volume) & 95,8 & 22,0 \\
\hline Resolução ANP & $23 / 2010$ & $21 / 2009$ \\
\hline
\end{tabular}

\begin{tabular}{|l|c|}
\hline \multicolumn{1}{|c|}{ Característica } & Combustível \\
\cline { 2 - 2 } & Diesel \\
\hline Massa especifica a 20ํ $\mathrm{C}\left(\mathrm{kg} / \mathrm{m}^{3}\right)$ & 830,7 \\
\hline Teor de enxofre $\mathrm{mg} / \mathrm{kg}$ & 4 \\
\hline Número de cetano derivado & 50,8 \\
\hline Resolução ANP & $40 / 2008$ \\
\hline
\end{tabular}

2.2.4 Procedimentos de preparo e impregnação dos cartuchos para coleta de aldeídos

Cartuchos impregnados, da marca Waters, são lavados com aproximadamente $5 \mathrm{ml}$ de acetonitrila para retirada do DNPH. A solução do DNPH para reimpregnação do cartucho é preparada pelo aquecimento do excesso de DNPH em $200 \mathrm{ml}$ de acetonitrila por 1 hora. Transfere-se o sobrenadante e inicia-se a evaporação do solvente. Lavar os cristais com acetonitrila e repetir o procedimento de evaporação de $200 \mathrm{ml}$ do solvente acrescentados aos cristais. Adicionar $60 \mathrm{ml}$ de acetonitrila, e a partir desta solução supersaturada de DNPH, diluir e adicionar o ácido fosfórico.

Após a limpeza com acetonitrila, os cartuchos são reimpregnados com a solução saturada de DNPH e ácido fosfórico. Esta impregnação é feita com seringa de vidro, de $50 \mathrm{ml}$, e com um controlador de vazão na própria seringa. Esta impregnação não pode ser forçada, ou seja, o cartucho é encaixado na seringa, e a passagem do reagente para o cartucho deve ser feita com o peso do próprio embolo da seringa. Isto para assegurar que o efluente não crie caminhos alternativos dentro do cartucho, e para que a impregnação seja uniforme. Em seguida o cartucho é levemente secado com gás nitrogênio, evitando a contaminação das mangueiras do sistema impinger com solução de DNPH. 
Após a impregnação, os cartuchos são armazenados sob-refrigeração, evitando ao máximo a contaminação pelo ambiente externo, diminuindo tambéma velocidade de possíveis reações, devido às baixas temperaturas.

O preparo pré-ensaio se dá com a instalação do cartucho no sistema impinger, respeitando a direção de fluxo indicado pelo fabricante, e com uma vazão regulada para $1,5 \mathrm{~L} / \mathrm{min}$. O sistema realiza um teste de verificação de vazamentos, neste momento, o cartucho já deve estar instalado no sistema.

A coleta ocorre normalmente, de acordo com o ciclo de emissões ao qual o veículo está sujeito. Nos experimentos realizados o ciclo de condução em dinamômetro se baseou nas normativas europeias de coleta de emissões em dinamômetro de chassis [24, 25].

Para a transferência da amostra impregnada no cartucho é utilizado um fluxo $5 \mathrm{ml}$ de acetonitrila através do cartucho, respeitando o sentido de fluxo indicado, e com pressão ambiente. Esta amostra é transferida para um balão e avolumada em $5 \mathrm{ml}$.

O cartucho passa por uma nova limpeza, e é armazenado para ser reutilizado, passando por um novo processo de impregnação.

Uma alíquota da amostra do balão de $5 \mathrm{ml}$ é injetada em cromatógrafo de fase líquida, e os aldeídos e cetonas são quantificados de acordo com a metodologia prescrita na NBR 12026 [8].

\section{RESULTADOS}

Na Figura 8 são demonstrados os resultados obtidos no ensaio de correlação de acordo com o método 1, coletados nas duas linhas disponíveis no amostrador de aldeídos Horiba, ou seja, realizando a coleta de gás pelo método impingers e por cartuchos. Nesta condição se utiliza o controle e a medição de vazão do próprio amostrador Horiba. Os resultados abaixo são relativos ao motociclo abastecido com gasolina A22.

Pode-se observar que os resultados obtidos são correlatos, apresentando, em geral, uma diferença média menor que $5 \%$ entre os métodos de coleta por impingers e cartuchos. 


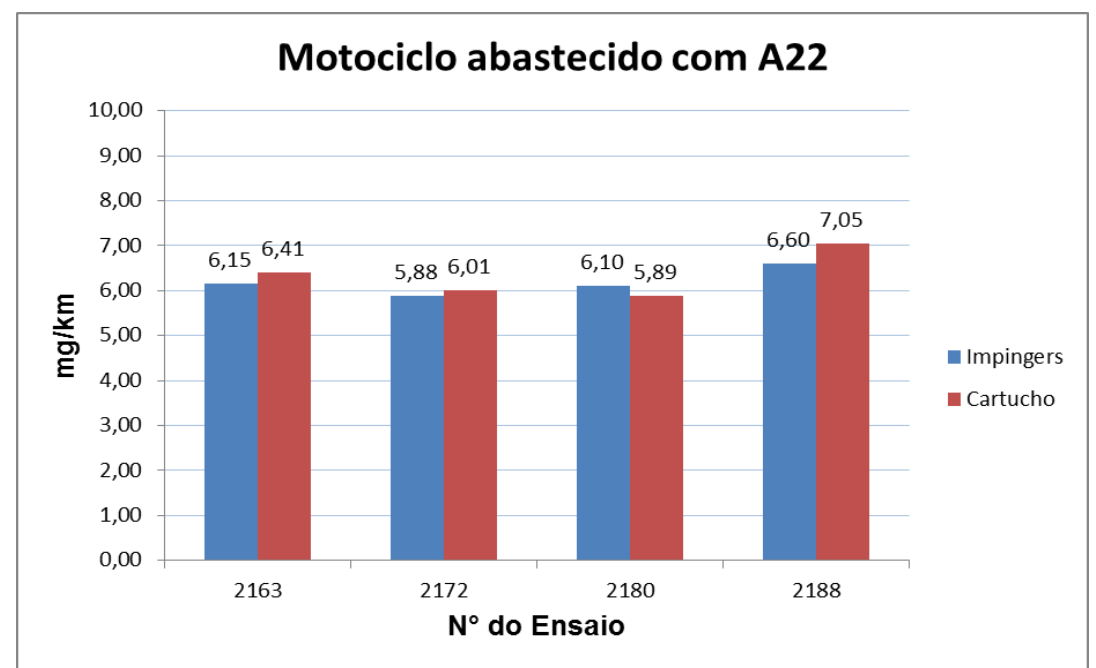

Figura 8 Resultados de aldeídos totais comparando coleta de gases por meio de impingers e cartuchos. Motociclo abastecido com gasolina A22.

Fonte: Os autores (2014)

Na Figura 9 são demonstrados os resultados obtidos no ensaio de correlação ainda de acordo com o método 1. Neste caso foi ensaiado o veículo Diesel, abastecido com diesel padrão de referência.

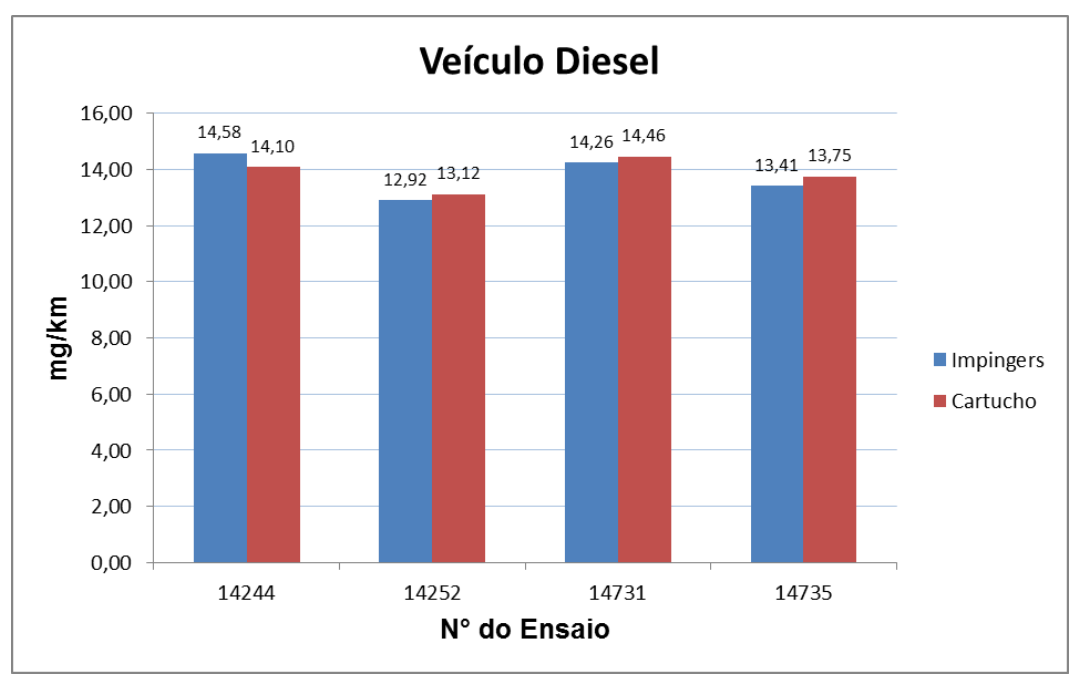

Figura 9 Resultados de aldeídos totais comparando coleta de gases por meio de impingers e cartuchos. Veículo leve Diesel, abastecido com diesel padrão de referência.

Fonte: Os autores (2014)

Os testes cujos resultados são apresentados na Figura 10 foram executados de acordo com o método 2. Assim como nos casos anteriores, as coletas dos gases de exaustão também foram simultâneas. A primeira por impingers; a segunda por cartuchos utilizando-se da unidade móvel autônoma (UA) para amostragem. Os resultados se referem a ensaios do motociclo abastecido com etanol hidratado (EHR). 


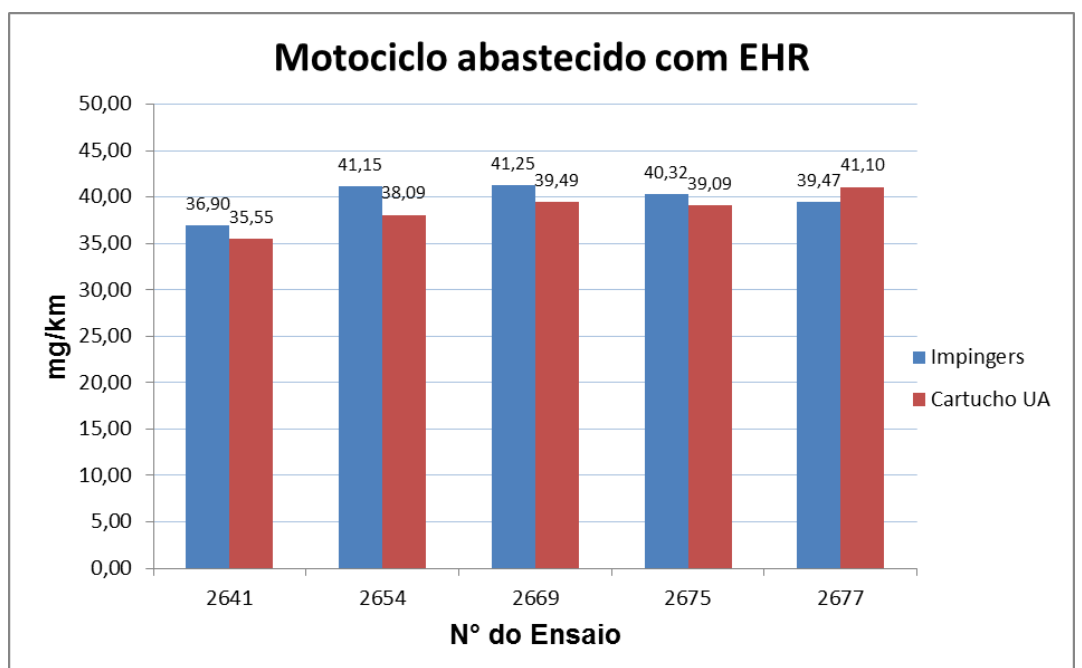

Figura 10 Resultados de aldeídos totais comparando coleta de gases por meio de impingers e cartuchos. Motocicleta abastecida com etanol hidratado EHR.

Fonte: Os autores (2014)

\section{CONCLUSÕES}

Os resultados apresentam uma correlação aceitável entre os métodos de coleta de aldeídos por meio de cartuchos e impingers com diferenças, em geral, menores de $5 \%$ entre os dois métodos.

Um aspecto relevante do processo foi o aprendizado da equipe envolvida neste trabalho, com a construção de um protótipo, chamado de unidade móvel autônoma, que possibilitou uma flexibilização da coleta de gases devido as suas características dimensionais e de construção, o qual pode ser instalado e integrado aos sistemas de coleta de gases já existentes, como smart sampler em sala de teste de motores e CVS em sala de chassi.

O próximo passo, e objetivo principal do desenvolvimento da unidade coletora de aldeídos, será a realização de testes da unidade móvel em bancadas de motores, para comprovação de seu desempenho na coleta de aldeídos.

Outro fato que merece destaque é a economia do solvente acetonitrila nas análises de aldeídos pela metodologia de cartuchos impregnados com DNHP. No procedimento de preparo e análise com o método impinger, são utilizados cerca de $500 \mathrm{ml}$ de acetonitrila para cada ensaio, considerando 3 fases do ciclo mais a fase do ar de diluição. $\mathrm{Na}$ análise com o cartucho, são utilizados cerca de $100 \mathrm{ml}$ de acetonitrila, também considerando as 3 fases, mais o ar ambiente. A economia de solvente pode chegar a cerca de $400 \mathrm{ml}$. 


\section{AGRADECIMENTOS}

Os autores agradecem ao Ministério da Ciência e Tecnologia e ao CNPq (Conselho Nacional de Desenvolvimento Científico e Tecnológico) pelo apoio à realização deste trabalho. Agradecem também à equipe do Laboratório de Emissões Veiculares do Lactec, onde foram realizados os testes de emissões, e ao PRODETEC (Programa de Pós-graduação em Desenvolvimento de Tecnologia).

\section{REFERÊNCIAS}

[1] CONAMA. Resolução CONAMA N403/2008 - Dispõe sobre a nova fase de exigência do Programa de Controle da Poluição do Ar por Veículos Automotores-PROCONVE para veículos pesados novos (Fase P-7) e dá outras providências". Publicação DOU no 220 , de 12/11/2008, pp. 92-93.

[2] YAO, Y. C.; TSAI, J. H.; CHIANG, H. L. Effects of ethanol-blended gasoline on air pollutant emissions from motorcycles. Science of the Total Environment, 407 (2009) 5257-5262, 12 July 2009.

[3] THELES, O. C. Modelagem da formação e emissão de aldeídos em motores operando com etanol. 128f. Dissertação (Mestrado em Engenharia Mecânica) - Programa de Pós-Graduação em Engenharia Mecânica, Pontifícia Universidade Católica de Minas Gerais, Minas Gerais, 2007.

[4] KUMAR, S.; NAYEK, M.; KUMAR, A.; TANDON, A.; MONDAL, P.; VIJAY. A.; BHANGALE, U. D.; TYAGI, D. Aldehyde, Ketone and Methane emissions from motor vehicle exhaust: a critical review. American Chemical Science Journal, 1(1): 1-27, June 2011. Disponível <www.sciencedomain.org>. Acesso em 19/01/2012.

[5] ABRANTES, R.; ASSUNÇÃO, J. V.; HIRAI, E. Y. Caracterização das emissões de aldeídos de veículos do ciclo diesel. Revista Saúde Pública, 2005, 39(3), 479-485.

[6] SANDSTRÖM-DAHL, C. METEV - Measurement Technologies for Emissions from Ethanol Fuelled Vehicles. International Energy Agency - Advanced Motor Fuels. AVL MTC 9711, 2009/11.

[7] KRAHL, J.; MUNACK, A.; BAHADIR, M.; SCHUMACHER, L.; ELSER, N. Review: Utilization of Rapeseed Oil, Rapeseed Oil Methyl Ester or Diesel Fuel: Exhaust Gas Emissions and Estimation of Environmental Effects. International Fall Fuels \& Lubricants Meeting \& Exposition. 962096, October 14-17 1996.

[8] ASSOCIAÇÃO BRASILEIRA DE NORMAS TÉCNICAS. NBR 12026: Veículos rodoviários automotores leves - Determinação da emissão de aldeídos e cetonas contidas no gás de escapamento, por cromatografia líquida - Método DNPH, 2009.

[9] BRASIL. MINISTÉRIO DO MEIO AMBIENTE, Resolução CONAMA ㄲo 3. Publicada no DOU de 25 de agosto de 1989, Seção 1, páginas 14.713.

[10] ASSOCIAÇÃO BRASILEIRA DE NORMAS TÉCNICAS. NBR 6601: Veículos rodoviários automotores leves - Determinação de hidrocarbonetos, monóxido de carbono, óxidos de nitrogênio, dióxido de carbono e material particulado no gás de escapamento, 2012. 
[11] CALIFORNIA ENVIRONMENTAL PROTECTION AGENCY. AIR RESOURCES BOARD, Standard operating procedure for the determination of aldehyde and ketone compounds in automotive source samples by high performance liquid chromatography. SOP MLD 104. April 1, 2001.

[12] CODE OF FEDERAL REGULATIONS (CFR), Title 40, Part 86. Disponível em: http://ecfr.gpoaccess.gov/cgi/t/text/text-

idx?c=ecfr\&tpl=/ecfrbrowse/Title40/40cfr86_main_02.tpl. Acesso em 30/06/12 às $13: 03 \mathrm{~h}$.

[13] SILVA, A.V.F.; Carvalho, F.L.; Bacci, G.V. Métodos Alternativos de Coleta de Amostras de Aldeídos nas Emissões veiculares Visando Redução do Consumo e do Descarte de Acetonitrila. XVII SIMEA, Brasil, 2009

[14] DAEMME, L. C.. Estudo da emissão de aldeídos em motociclos. Dissertação (Mestrado) - Instituto de Tecnologia para o Desenvolvimento - LACTEC, Programa de Pós-Graduação em Desenvolvimento de Tecnologia PRODETEC. Curitiba, 2012.

[15] ZHANG, Z.H.; Cheung, C.S.; Chan, T.L.; Yao, C.D. Experimental investigation on regulated and unregulated emissions of a diesel/methanol compound combustion engine with and without diesel oxidation catalyst. Science of the Total Environment, 408 (2010) 865-872, Elsevier, 2010.

[16] ZHU, R.; Cheung C.S.; Huang Z; Wang, X. Regulated and unregulated emissions from a diesel engine fueled with diesel fuel blended with diethyl adipate. Atmospheric Environment 45 (2011) 2174 -2181, Elsevier, 2011.

[17] MELO, T.C.C; ROCHA, J.R.S; PENTEADO, R.; Ferreira, R.S. Proposal of Aldehydes Measuring Methods for Light and Heavy Duty Diesel Vehicles. SAE International, 2010-36-0407, 2010.

[18] DAEMME, L.C.; PENTEADO, R.; FERREIRA, R.S. Estudo das Emissões de Aldeídos Geradas em Motociclos. XVIII SIMEA, Brasil, 2010.

[19] PENTEADO, R.; DAEMME, L.C.; MELO, T.C.C. An Experimental Investigation on Regulated and Unregulated Emissions from Four 4-Stroke GasolinePowered Motorcycle. SAE 2012-01-1098, 2012.

[20] TAN, P.Q.; Hu, Y.; LOU, D. Regulated and unregulated emissions from a lightduty diesel engine with different sulfur content fuels. Fuel Magazine, Elsevier, 2009.

[21] ABRANTES, R.; ASSUNÇÃO, J.; HIRAI, E.Y. Caracterização das emissões de aldeídos de veículos do ciclo diesel. Revista Saúde 39(3): 479-85. São Paulo, 2005.

[22] BOSTEELS, D.; et al. Regulated and non-regulated emissions from modern european passenger cars. Revista SAE, 01-1516, 2006.

[23] SAWANT, A. A. et al. Real-world Emissions of Carbonyl Compounds from InUse Heavy-duty Diesel Trucks and Diesel Back-Up Generators (BUGs). Atmospheric Environment 41 (2007) 4535-4547.

[24] DIRECTIVE, Council. 70/220/EEC of 20 March 1970. Official Journal L, v. 80.

[25] EUROPEAN UNION. The European Parliament, on certain components and characteristics of two or three-wheel motor vehicles - 97/24/EC, 17/07/1997. 